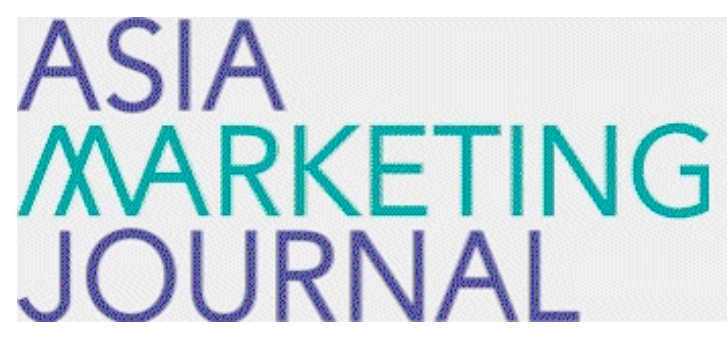

ASIA MARKETING JOURNAL

Volume 18 | Issue 1

Article 3

4-30-2016

\title{
Interaction Effects of Arousal Level of Positive Ambient Emotion and Advertisement Type on Product Evaluation
}

Nak Hwan Choi

Tamir Oyunbileg

Follow this and additional works at: https://amj.kma.re.kr/journal

Part of the Marketing Commons

\section{Recommended Citation}

Choi, Nak Hwan and Oyunbileg, Tamir (2016) "Interaction Effects of Arousal Level of Positive Ambient Emotion and Advertisement Type on Product Evaluation," Asia Marketing Journal: Vol. 18 : Iss. 1 , Article 3.

Available at: https://doi.org/10.15830/amj.2016.18.1.37

This Article is brought to you for free and open access by Asia Marketing Journal. It has been accepted for inclusion in Asia Marketing Journal by an authorized editor of Asia Marketing Journal. 


\title{
Interaction Effects of Arousal Level of Positive Ambient Emotion and Advertisement Type on Product Evaluation
}

\author{
Nak Hwan Choi* \\ Tamir Oyunbileg**
}

\begin{abstract}
The purpose of this study is to show that the effectiveness of utilitarian versus hedonic attributefocused advertisement on product evaluation depends on the arousal level of positive emotion, and to explore mediation effect of cognitive response to utilitarian attribute-focused advertisement and affective response to hedonic attribute-focused advertisement on the effectiveness of utilitarian versus hedonic attribute-focused advertisement. This research employs a 2 (arousal level: mild vs. elevated) $\times 2$ (advertisement type: utilitarian vs. hedonic) between-subjects design, and 200 undergraduate students participate in the experiment, in which there are 50 students at each experimental group. The results of ANCOVA with positive emotion level as a covariate on advertised product evaluation show significant interaction effect of arousal level and advertisement type, and no effect of positive emotional level. Both of the mediation effects of the cognitive response and those of the affective response are significant. Participants under mild (elevated) arousal of positive emotion more positively evaluate the product in utilitarian (hedonic) attribute-focused advertisement. The positive effect of utilitarian (hedonic) attributefocused advertisement on product evaluation is partially mediated by cognitive (affective) response to the advertisement when consumers are under the mild (elevated) arousal of positive emotion. The results of this study show that advertisers should use utilitarian (hedonic) attribute-focused advertisement to consumers under the mild (elevated) arousal of ambient positive emotion, which should be searched by exploring what kind of event they have experienced.
\end{abstract}

Key words: advertisement type, affective response, arousal, cognitive response

* Professor, Dept. of Business Administration, Chonbuk National University, South Korea (cnh@ jbnu.ac.kr)

** Lecturer, School of Business Administration and Humanities, Mongolian University of Science and Technology, Mongolia (tamiraa_0127@yahoo.com) 


\section{Introduction}

Affect can be explained as a combination of valence, which refers to the positive or negative nature of an affective experience, and arousal, which is defined as the subjective experience of energy mobilization ranging from sleepy to frantic excitement (Mehrabian \& Russel, 1974). For example, obtaining a dream job at an important stage in life is likely to lead to an elevated arousal of positive emotion, whereas receiving small incentives in ordinary daily life is likely to lead to a mild arousal of positive emotion.

A number of past studies have investigated the influence of emotional valence on choice behaviors. For instance, feeling happy can be a success signal of achieving a pursued goal, and can lead to happiness maintenance behaviors. People in positive ambient mood tend to refrain from mood-threatening behaviors. However, according to the literature about emotions, differences in affective meaning can be described by arousal as well as by valence (Bradley \& Lang, 1994). For example, though both excitement (elevated arousal) and peacefulness (mild arousal) are positive-valence emotion, excited (peaceful) consumers evaluate the adventurous (serene) vacation more favorably than peaceful (excited) consumers (Kim et al., 2010). Further, Fedorikhin and Patrick (2010) postulated that mild arousal of positive emotion makes people more likely to choose a healthy option over a sinful hedonic option when faced with temptation, but the contrast effect is true with an elevated arousal of positive emotion.

For managing advertisement, interesting questions arise: How do marketers advertise their products to persuade consumers who are experiencing positive ambient emotion with different arousal levels (i.e., mild vs, elevated)? How do consumers' product evaluations change when the product is advertised using different attribute focuses (i.e., utilitarian vs. hedonic)? Little attention have been paid to the interactive impact of arousal level (mild vs. elevated) and advertisement type (utilitarian-focused vs. hedonicfocused) on advertised product evaluation.

In this article, we examine how product evaluations are influenced by the interplay between the advertisement type and the arousal level of a positive ambient emotion that is unrelated to the product, and we investigate the underlying mechanisms for the interaction effect by examining the mediating roles of cognitive and affective responses to the advertisement.

\section{Theoretical Background and Hypotheses Development}

\subsection{Hedonic vs. Utilitarian Attribute- Focused Advertisements}

It is now ubiquity that all products are gen- 
erally classified into two categories: utilitarian and hedonic. Broadly speaking, hedonic goods (e.g. designer clothes, sports cars, luxury watches, chocolate fall etc.) provide more experiential consumption, fun, pleasure, and excitement, whereas utilitarian goods (e.g. microwaves, minivans, personal computers, etc.) are primarily instrumental and functional.

Furthermore, previous research suggests that any product can contain both hedonic and utilitarian attributes with some degree (Chernev, 2004; Hirschman \& Holbrook, 1982). Utilitarian 'size, speed) concern the ability that a product can execute to fulfill consumers' needs that serve for maximizing desirable end state or minimizing undesirable end state in long-term (Chernev, 2004). But hedonic attributes of a product (i.e., car design and color) are more associated with the joyful and the sensorial characteristics that serve for providing pleasantness and immediate gratification (Botti \& Mcgill, 2011).

Theories of advertising effects based on cognitive models postulate that advertising affects the product evaluation by changing consumers' beliefs about the product (e.g., Batra \& Ray, 1986). However, affective attitudes toward the advertisement could also seem to linearly influence the attitude toward the advertised product (e.g., Burke \& Edell, 1989; Pham et al., 2013) because the feelings and the thoughts are generally considered as two independent mediators in evaluation systems (Burke \& Edell, 1989). Exposure to advertisement can generate the particular types of nodes related to it. Advertisements can convey meanings of products that go far beyond their physical features by which consumers could draw upon associations or memory network to catch up with the implicit meaning they convey (Pham et al., 2013). The most salient attributes can receive more attention and provide more insight into a task (Chernev, 2004). Therefore, advertisement can change products into different entities by using either utilitarian or hedonic attribute-focused framing as its highlight.

\subsection{Interaction Effect of Arousal levels of Positive Emotion and Advertisement types on Product Evaluation}

According to mood congruency theories, individuals' emotional valence- positive or negativepolarizes the judgment. A network theory suggests that positive affect-laden information is more efficiently processed under positive mood, whereas negative affect-laden information has more efficient processing advantage under negative mood because people occupy affectively associated memory (Forgas \& Bower, 1987). Furthermore, mood-as-information theory (Schwarz \& Clore, 1983) proposes that when making a judgment, people use "How do I feel about it?" heuristic, wherein the prevailing mood is misattributionally used as one obvious gauge. Further, many researchers have postulated that people 
under the positive mood do not engage in proactive behavior in anticipation of the moodthreatening cues (Mood-maintenance theory; Clark \& Isen, 1982). Also, the hedonic contingency hypothesis suggested that happy people, who are more sensitive to hedonic contexts since they think fewer actions will improve the happy mood, more carefully choose activities to maintain the mood (Wegener \& Petty, 1994). In the past studies, the judgment is a function of the direction of valence of emotion, which is characterized as a static affective evaluation theory (Andrade, 2005). However, when ambient positive emotion is attributed to task performance, arousal level of the emotion becomes different according to the degree to which the task performance is self-relevant. Past studies on the roles of emotional valence did not give attention to the roles of arousal level of the positive ambient emotion.

In contrast to the valence-based theories, a growing body of study has considered that emotion can be explained through combining its valence- positive and negative- and its arousal degree- mild and elevated (e.g., Gorn et al., 2001; Libkuman et al., 1999; Mehrabian \& Russel, 1974). Varying arousal levels of any positive emotion ranging from drowsiness to excitement which can generally be categorized into mild arousal and elevated arousal exert substantively distinct impacts on consumer behavior (Fedorikhin \& Patrick, 2010).

Earlier work revealed that elevated arousal in any emotion can narrow the focus of attention to enable a person to mainly concentrate on more salient stimuli (e.g., Libkuman et al., 1999). Positive elevated emotion induces consumers to have hedonic consumption goal that provide immediate reward because the emotions prompt them to deplete cognitive ability (Sanbonmastsu \& Kardes, 1988), and help feel licensed not to act in a virtuous way (Dunning, 2007) and could lead them to do self-gratification behavior. The positive elevated emotion can lead to overeating in restrained conditions (Cools et al., 1992), and more reliance on the advertisement's affective tone when evaluating the advertisement (Gorn et al., 2001). However, mild arousal of positive emotion generally gives consumers mental energy to be cognitively motivated for long-term rewards to help pursue the long-term success and well-being rather than immediate rewarding when faced with the choice between healthy and nonhealthy options (Fedorikhin \& Patrick, 2010). In the view of goal-attribute or task compatibility principle (Fischer et al., 1999; Tversky, Sattath, \& Slovic, 1988), the weighting value of inputs is increased by their compatibility with the output, and the most prominent attributes receive more weight in tasks that require differentiating between the alternatives. Display of compatible message could elicit a regulatory mean to achieve the goal. Therefore, product evaluations are a function of the degree of the compatibility.

In sum, hedonic (utilitarian) attributes of the 
product may be compatible with the goal of the consumers under elevated- (mild-) aroused positive emotion because the elevated (mild) positive emotion induces an increased focus on immediate pleasures and rewards (long-term rewards). Therefore, we suggest the following hypotheses about the interactive function of arousal level of positive ambient emotion and advertisement type on advertised product evaluation.

Hypothesis 1a: When consumers are under mild arousal of positive emotion, they evaluate the product in utilitarian attribute-focused advertisement more positively than the one in hedonic attribute-focused advertisement.

Hypothesis 1b: When consumers are under elevated arousal of positive emotion, they evaluate the product in hedonic attribute-focused advertisement more positively than the one in utilitarian attribute-focused advertisement.

\subsection{Mediating Roles of Cognitive and Affective Response to Advertisement}

The advertisement framing with the specific product attributes may induce assimilative interpretation effects. For example, framing the target "car" product with special hedonic attribute such as "luxurious" or "brand new designed" may result in assimilated perception such as "This is a luxurious car," or "This is a brand new car”. Puto and Wells (1984) postulated that transformational advertisement focused on the emotional aspects of the advertised product connects the consumers so tightly with the expected experience of using the advertised product, which should generate more affective responses to the advertisement. In contrast, informational advertisement that focuses on the product's utilitarian attribute information should generate more cognitive responses to the advertisement (Edell \& Burke, 1987). Accordingly, hedonic attribute-focused advertisement can predominantly evoke affective (vs. cognitive) responses, and the reverse is true for utilitarian attribute-focused advertisement.

On the other hand, studies on context effects and information accessibility effects (see Schwarz \& Bless, 1992) suggested that particular product attributes in harmony with certain contexts, are more accessible when evaluating the product. Also, a study of "think" vs. "feel" framing effects in persuasion showed that the framing has a great influence on persuasion if the frame is compatible with the target consumers' current attitude orientation (Mayer \& Tormala, 2010). Mild arousal of positive emotion helps consumers have cognitively motivated orientation toward long-term rewards, whereas elevated arousal of positive emotion leads to affectively motivated orientation to immediate rewards (e.g., Fishbach \& Labroo, 2007). Therefore alternative framing for the same options can entail intensive changes in choice (e.g., Tversky \& Kahneman, 1986). These results of past studies are in accordance with the compatibility principle that 
postulates "...the more important dimension of a decision problem looms larger in choice..." (Tversky, Sattath, \& Slovic, 1988, p. 371).

In addition, positive elevated emotion helps consumers to deplete cognitive ability and have hedonic consumption goal (Sanbonmastsu \& Kardes, 1988), which in turn, could lead them to the place of doing self-gratification behavior. The positive elevated emotion can help them give more attention to affective aspects of the advertisement exposed to them (Gorn et al., 2001). However, positive mild emotion generally helps consumers be cognitively motivated for long-term rewards by giving mental energy to them when deciding the choice between healthy and nonhealthy options (Fedorikhin \& Patrick, 2010). Therefore the positive mild emotion could help them give more attention to cognitive aspects of the advertisement.

On the other hand, the increased cognitive (affective) response to the advertisement could signal consumers under mild (elevated) arousal of positive emotion, who are cognitively (affectively) motivated for long-term rewards (immediate rewards), that the advertised product is compatible with their long-term (immediate) rewards.

Taken together, for the consumers under mild arousal of positive emotion, the advertisement should afford them to generate more cognitive (vs. affective) response to the advertisement, if so, they are more likely to positively evaluate the advertised product. But the reverse is true for the consumers under elevated arousal of positive emotion. Thus, cognitive and affective response to the advertisement could be a critical factor for understanding the underlying mechanism operating in the interactive roles of arousal level of positive emotion and advertisement types on product evaluation. To illustrate, we develop the following hypotheses.

Hypothesis 2a: When consumers are under mild arousal of positive emotion, the positive effect of utilitarian attribute-focused advertisement on product evaluation will be mediated by cognitive response to the advertisement.

Hypothesis 2b: When consumers are under elevated arousal of positive emotion, the positive effect of hedonic attribute-focused advertisement on product evaluation will be mediated by affective response to the advertisement.

\section{Experimental Design and Measurement}

\subsection{Experimental Design and Development of Scenarios and Advertisements}

This research employs a 2 (arousal level of positive emotion: mild vs. elevated) $\times 2$ (advertisement type: utilitarian vs. hedonic) between-subjects design, uses a restaurant service as an experimental object for two reasons. 
First, student participants are familiar with restaurant services and tend to experience the service in their daily lives regardless of their emotional arousal levels. Second, restaurants can provide both salient hedonic and utilitarian attributes, allowing us to create two types of advertisement as independent variable in this experiment. A restaurant with the fictional name PALLADIO unknown to the participants was used to avoid response biases from the participants' familiarity with an experimental object.

Authors classify restaurant service attributes as shown in 〈Table 1〉 to develop two types of advertisements: utilitarian attribute-focused advertisement (see Appendix I) and hedonic attribute-focused advertisement (see Appendix II).

This research adopts a "scenario" method to induce different levels of arousal of positive emotion as moderating variable. For the scenario triggering mild arousal of positive emotion, the event of finding a part-time job with good conditions was described (see Appendix III). For the scenario inducing elevated arousal of positive emotion, we described the good news that $(\mathrm{s})$ he has succeeded in a job interview needed to enter famous company (see Appendix
IV). The amounts of information to process in the two scenario descriptions were equivalent.

\subsection{Procedure and Measurement}

We asked participants to read the scenario and to imagine that they were actually experiencing the scenario event. After reading the scenario, participants responded to the series of questions measuring the level of attention paid to the scenario, positive emotion, and arousal level. The level of attention to the scenario and the advertisement was measured using three items (attention, involvement, and commitment) (see Labroo \& Rucker, 2010). We measured positive emotion by using six items (happy, pleased, delighted, satisfied, eager, and joyful) (Watson et al., 1988) and positive arousal level by using five items (jittery, active, excited, positively aroused, and stimulated) (see Fedorikhin $\&$ Patrick, 2010) on 7-point scales (1 = not at all, 7 = a lot).

Next, we instructed the participants to read the restaurant advertisement with time limitation of ten seconds (sufficient time to read the advertisement), and were asked to answer a set

\section{$\langle$ Table 1〉 Classification of Restaurant Attributes}

\begin{tabular}{|l|l|}
\hline \multirow{2}{*}{ Hedonic attributes } & $\begin{array}{l}\text { Taste of food, Interior decoration, Size of indoor space, Comfortable seating, } \\
\text { User image, Outward appearance, Atmosphere, Friendliness of employees, } \\
\text { Comfortable place to socialize, Overall impression. }\end{array}$ \\
\hline Utilitarian attributes & $\begin{array}{l}\text { Speed of service, Healthy menu options, Variety of menu choices, Special } \\
\text { discounts, Coupons, Location, Nutrition information for menu items, Hours of } \\
\text { operation, Enough place for parking, Servers' knowledge about menu. }\end{array}$ \\
\hline
\end{tabular}


of questions that cover advertisement characteristics, affective and cognitive response, and the restaurant evaluation (dependent variable). Advertisement characteristics were measured by using three items anchored at 1 (performance/ cognitive appeal/cognitive urge) and 7 (hedonic/ affective appeal/affective urge) (Fedorikhin \& Patrick, 2010). Affective response were measured by using eight semantically different affective reaction scales: "I felt love when I saw this advertisement," "I was delighted when I saw this advertisement," "I felt happy when I saw this advertisement," "I felt calm when I saw this advertisement," "I was excited when I saw this advertisement," "I was relaxed when I saw this advertisement," "I felt acceptable when I saw this advertisement," "I felt joy when I saw this advertisement"; and cognitive responses were measured by seven semantically different cognitive reaction scales: "I thought this advertisement is useful," "I thought this advertisement is wise," "I thought this advertisement shows safety of using the restaurant," "I thought this advertisement is beneficial," "I thought this advertisement is valuable," "I thought this advertisement is perfect," "I thought this advertisement stresses wholesomeness," on 7-point scales ( $1=$ not at all, $7=$ a lot), based on the "measures of affect and cognition" which were developed and validated by Crites et al. (1994). Restaurant evaluation was measured using six items: "I like this restaurant," "I favor this restaurant," "I think this restaurant is attractive,"
"I think the quality of this restaurant is good," "I would like to visit this restaurant," and "I think this restaurant is pleasant" on 7-point scales ( $1=$ not at all, 7 = very much), which are adopted from previous studies (Fennis \& Bakker, 2001; Zhang \& Khare, 2009). Finally, participants answered questions about demographic information and were debriefed.

\subsection{Pretest and Participants}

In pretest, we selected 40 undergraduate students of large university, divided them into two groups which include 20 students for each. And we distributed mild arousal-inducing scenario questionnaire to one group and distributed elevated arousal-inducing scenario questionnaire to the other group, and asked them to read the scenario distributed to answer on the items related to the positive emotion and the arousal. Both of the two groups showed positive emotions $\left(\mathrm{M}_{\text {mild positive }}=4.33, \mathrm{SD}=1.45 ; \mathrm{M}_{\text {elevated positive }}\right.$ $=6.05, \mathrm{SD}=.67)$; and as expected, there was significant arousal difference between the two groups $\left(\mathrm{M}_{\text {mild positive }}=4.17, \mathrm{SD}=.50 \mathrm{vs}\right.$. $\mathrm{M}_{\text {elevated positive }}=5.21, \mathrm{SD}=1.05 ; \mathrm{t}(38)=$ -3.982, $\mathrm{p}<.01$ ). We selected 40 undergraduate students again, and randomly distributed 40 advertisement questionnaires (20 for each type of advertisement) to them and asked them to read the advertisement distributed to answer on the items related to the advertisement characteristics. Advertisement characteristics were 
shown to be different between two groups divided by advertisement type read by the participants (Mutilitarian advertisement $=2.03, \mathrm{SD}$ $=.96$ vs. Mhedonic advertisement $=6.38, \mathrm{SD}$ $=.55 ; \mathrm{t}(38)=-17.54, \mathrm{p}<.01)$.

200 undergraduate students of the university participated in the main study for class credit and they were randomly assigned to one of four experimental conditions (50 for each condition). All of them were told that they would be participating in two short studies and they also had a chance to win a reward ( $\$ 10$ gift card for $10 \%$ of the participants). $58.5 \%$ of the participants were male and 95\% of them were belonged to the "20 - 29 years old" category.

\section{Empirical Results}

\subsection{Confound and Manipulation Check}

The results of one-way ANOVA showed no differences of attention to scenario among the four conditions $(F(3,196)=.294, N S)$, and also no differences of attention to advertisements among the four $(F(3,196)=.086, N S)$. Thus, participants' attention levels paid to the scenarios and advertisements were perceived to have no confounding effects on the results of testing the hypotheses.

We conducted confirmatory principal factor analysis with SPSS 18.0 on the items measur- ing positive emotion and arousal level, and also conducted the analysis on the items measuring cognitive response, affective response, and advertised product evaluation. Varimax rotation removed pos5 (eager) and aro4 (positively aroused) since they were highly loaded on both of the two factors. Cog3 (safety), af4 (calm), and af6 (relaxed) were also removed because they were highly loaded on other factors. The values of items for each construct were averaged and used in following empirical study.

Next, the results of $t$-test showed positive emotions in both the mild and the elevated $\left(M_{\text {mild positive }}=4.40, S D=1.28 ; M_{\text {elevated positive }}=\right.$ $6.26, S D=.77$ ), arousal level difference between the two scinario conditions $\left(M_{\text {mild positive }}\right.$ $=4.19, S D=.63$ vs. $M_{\text {elevated positive }}=5.23, S D$ $=1.09 ; t(198)=-8.158, p<.01)$, difference of advertisement characteristics between the advertisement types $\left(M_{\text {utilitarian advertisement }}=2.16\right.$, $S D=1.10$ vs. $M_{\text {hedonic advertisement }}=6.19, S D=$ $.75 ; t(198)=-30.166, p<.01)$. Thus, the manipulations for the arousal levels and advertisement types were succeeded.

\subsection{Testing hypotheses}

We conducted a 2 (positive ambient affect level: mild vs. elevated) $\times 2$ (advertisement type: utilitarian attribute-focused vs. hedonic attribute-focused) ANCOVA (with positive emotion as a covariate) on advertised restaurant evaluation. The restaurant evaluations of the 
four experimental groups are given in 〈Table 2〉. The results showed neither a main effect of arousal level $(F(1,195)=.45$, NS) nor a main effect of advertisement type $(F(1,195)$ $=3.16, \mathrm{NS})$. However there was a significant interaction effect $(F(1,195)=124.15, p<.01$, $\left.\eta_{\mathrm{p}}^{2}=.389,1-\beta=1.0\right)$, and positive emotion had no effect on evaluation $(F(1,195)=1.5, N S)$.

To better understand the interaction effect, we conducted separate analysis for each of the mild and the elevated. In the mild arousal of positive emotion condition, participants who exposed to the utilitarian attribute-focused advertisement more positively evaluated the restaurant than those who viewed the hedonic attribute-focused advertisement $(F(1,99)=$ 76.96, $\left.p<.01, \eta_{\mathrm{p}}^{2}=.440,1-\beta=1.0\right)$, whereas the reverse was true in the elevated arousal of positive emotion condition $(F(1,99)=48.98, p$ $\left.<.01, \eta_{\mathrm{p}}^{2}=.333,1-\beta=1.0\right)$. Thus, the hypotheses $1 \mathrm{a}$ and $1 \mathrm{~b}$ were supported.

Before testing the hypotheses $2 \mathrm{a}$ and $2 \mathrm{~b}$, oneway ANOVAs were conducted on the cognitive and affective responses to each advertisement.
As expected, participants in the utilitarian attribute-focused advertisement condition reported higher cognitive (vs. affective) response, whereas the reverse was true for those in the hedonic attribute-focused advertisement condition $\left(M_{\text {cognitive response }}=4.17, S D=1.32\right.$ vs. $M_{\text {cognitive response }}=3.05, S D=.98 ; t(198)=$ 6.785, $p<.01)\left(M_{\text {affective response }}=4.19, S D=\right.$ 1.50 vs. $M_{\text {affective response }}=3.37, S D=1.17$; $t(198)=-4.315, p<.01)$.

To examine $\mathrm{H}-2 \mathrm{a}$ and $\mathrm{H}-2 \mathrm{~b}$, we checked the mediation roles of cognitive response and affective response on the relationship between advertisement type and product (restaurant) evaluation at each of the two groups: the mild arousal of positive emotion and the elevated arousal of positive emotion. Under the mild arousal condition, the advertisement type predicted product evaluation ( $\beta=-.663, p<.01$, $\left.R^{2}=.440\right)$, the advertisement type predicted cognitive response $\left(\beta=-.684, p<.01, R^{2}=\right.$ .467 ) but not affective response ( $\beta=.139$, $N S$ ), and cognitive response predicted product evaluation $\left(\beta=.719, p<.01, R^{2}=.517\right)$.

〈Table 2〉 Mean Product Evaluation of Each of the Groups

\begin{tabular}{|c|c|c|c|}
\hline & & \multicolumn{2}{|c|}{ Advertisement type } \\
\hline & & Utilitarian attribute-focused $\langle-1\rangle$ & Hedonic attribute-focused $\langle+1\rangle$ \\
\hline \multirow{2}{*}{ Arousal level } & Mild $\langle-1\rangle$ & $\begin{array}{c}5.18(1.17) \\
\quad(n=50)\end{array}$ & $\begin{array}{c}3.03(1.28) \\
\quad(n=50)\end{array}$ \\
\hline & Elevated $\langle+1\rangle$ & $\begin{array}{c}3.65(1.25) \\
\quad(n=50)\end{array}$ & $\begin{array}{c}5.22(.97) \\
(n=50)\end{array}$ \\
\hline
\end{tabular}

Note: The number in parentheses is the standard deviation; the number in brackets \langle\rangle is the value of the dichotomous variable in the experimental study; $n$ is the number of participants. 
However, when the product evaluation was regressed on both advertisement type and cognitive response, the effect of the advertisement type on product evaluation was attenuated ( $\left.\beta=-.322, p<.01, R^{2}=.572\right)$. In contrast, under the elevated arousal condition, the advertisement type predicted product evaluation $\left(\beta=.577, p<.01, R^{2}=.333\right)$, the advertisement type predicted affective response $(\beta=$ .499, $\left.p<.01, R^{2}=.249\right)$ but not cognitive response $\left(\beta=-.093, R^{2}=.44, N S\right)$, and affective response predicted product evaluation $(\beta=$ .511, $\left.p<.01, R^{2}=.261\right)$. However, when the product evaluation was regressed on both advertisement type and affective response, the effect of the advertisement type on product evaluation was attenuated $(\beta=.429, p<.01$, $\left.R^{2}=.400\right)$. Additionally, the results of Sobel test (Sobel, 1982) indicated that the mediation effects of both cognitive response under the mild emotion condition $\left(Z_{\text {cognitive under mild arousal }}=-6.87\right.$, $p<.01)$ and affective response under the elevated emotion condition ( $Z_{\text {affective under elevated arousal }}$ $=4.09, p<.01)$ were significant. Thus, the results supported $\mathrm{H}-2 \mathrm{a}$ and $\mathrm{H}-2 \mathrm{~b}$.

\section{V. summary and Discussion}

\subsection{Summary and Theoretical Implication}

Current research demonstrated that when consumers are under mild (elevated) arousal of ambient positive emotion, utilitarian (hedonic) attribute-focused advertisement positively influences on the advertised product evaluation, and explored the positive effect of advertisement type on product evaluation is partially mediated by cognitive (affective) responses to the utilitarian (hedonic) attribute-focused advertisement when consumers are under the mild (elevated).

To the best of our knowledge, our study is the first that explores both the interaction effects of the arousal levels and the advertisement type and the mediation roles of cognitive and affective responses. Therefore, firstly, the results of this study contribute to advertisement theory by exploring the interaction effects of the arousal level and advertisement type on product evaluation. Secondly, our study also contribute to the theory of consumer psychology by demonstrating that the cognitive (affective) response to the utilitarian (hedonic) attributefocused advertisement plays mediating roles on the advertisement effects when consumers are under the mild (elevated).

\subsection{Managerial Implication}

One tricky question in the application of this study is how advertising managers can separate customers based on their arousal level of positive ambient emotion. Finding right target consumers is an issue to the managers. It is 
possible that the arousal can be easily found in the real world. For example, a psychological state of the elevated (mild) arousal can be triggered by being accessed to marital transition from single to married status, social status transitions to validate his or her roles such as university graduation, or meeting with friend improved with age, etc. (becoming a long-distance runner, winning small incentives in ordinary life, ordinary meeting with an acquaintance, etc.). Therefore the managers should search the events that customers experienced in advance.

And although the arousal level can moderate product evaluation effects of advertisement type, at the core of our finding is how advertisers use the arousal level. In addition, from the perspective of the current research, advertisers should check whether their utilitarian (hedonic) attribute-focused advertisement would evoke enough cognitive (affective) response to the consumers under the mild (elevated) arousal of positive emotion before launching their advertisement to increase the effectiveness of it.

In sum, advertisers should search what kind of event the consumers have experienced, and use utilitarian (hedonic) attribute-focused advertisement when consumers are under the mild (elevated) arousal of ambient positive emotion. study could expand our findings to negative emotion context. Cognitive appraisal theories (e.g., Lerner \& Keltner, 2000) suggest that there can be motivational differences among the types of positive emotions. Therefore, future research should investigate the interaction effect in view of cognitive-appraisal differences among the specific types of positive emotion. Integrated emotional feelings about the product are different from ambient emotion, and could play important role in the target judgment especially when the integrated feelings are believed to be representative of the target (Pham et al., 2001). Therefore, the role of arousal level of integrative emotion on the effect of advertisement type should receive attention from researchers.

Previous study has dealt with the effectiveness of congruency between type of communication and type of product (e.g., Pham et al., 2013). Thus, one interesting question is remainedis a hedonic or utilitarian attribute-focused advertisement checked in the current study equally effective for a hedonic vs. utilitarian product? Future study should check this by considering the hedonic/utilitarian nature of the product.

〈Received August 3. 2015〉

〈Revised March 14. 2016〉

〈Accepted March 28. 2016〉

\subsection{Limitation and Future Research}

Current study investigated the interaction effects focused on only positive emotion. Future 


\section{References}

Andrade, E. B. (2005). "Behavioral consequences of affect: Combining evaluative and regulatory mechanisms," Journal of Consumer Research, 32(3), 355-362.

Batra, R., \& M. L. Ray (1986). "Affective responses mediating acceptance of advertising," Journal of Consumer Research, 13(2), 234249.

Botti, S., \& A. L. Mcgill (2011). "The locus of choice: personal causality and satisfaction with hedonic and utilitarian decisions," Journal of Consumer Research, 37(6), 1065-1077.

Bradley, M. M., \& P. J. Lang (1994). "Measuring emotion: The self-assessment manikin and the semantic differential," Journal of Behavior Therapy and Experimental Psychiatry, 25 (1), 49-59.

Burke, M. C., \& J. A. Edell (1989). "The impact of feelings on ad-based affect and cognition," Journal of Marketing Research, 26(1), 6983.

Chernev, A. (2004). "Goal-attribute compatibility in consumer choice," Journal of Consumer Psychology, 14(1 \& 2), 141-150.

Cools, J., D. E. Schotte, \& R. L. McNally (1992). "Emotional arousal and overeating in restrained eaters," Journal of Abnormal Psychology, 101(2), 348-351.

Crites, S. L., L. R. Fabrigar, \& R. E. Petty (1994). "Measuring the affective and $\operatorname{cog}^{-}$ nitive properties of attitudes: Conceptual and methodological issues," Personality and Social Psychology Bulletin, 20(6), 619-634. Dunning, D. (2007). "Self-image motives and consumer behavior: How sacrosanct selfbeliefs sway preferences in the marketplace," Journal of Consumer Psychology, 17(4), 237-249.

Edell, J. A., \& M. C. Burke (1987). "The power of feelings in understanding advertising effects," Journal of Consumer Research, 14 (3), 421-433.

Fedorikhin, A., \& V. M. Patrick (2010). "Positive mood and resistance to temptation: The interfering influence of elevated arousal," Journal of Consumer Research, 37(4), 698711.

Fennis, B. M., \& A. B. Bakker (2001). "Stay tuned-we will be back right after these messages: Need to evaluate moderates the transfer of irritation in advertising," Journal of Advertising, 30(3), 15-25.

Fischer, G. W., Z. Carmon, D, Ariely, \& G. Zauberman (1999). "Goal-based construction of preferences: Task goals and the prominence effect," Management Science, 45 (8), 1057-1075.

Fishbach, A., \& A. A. Labroo (2007). "Be better or be merry: How mood affects self-control," Journal of Personality and Social Psychology, 93(2), 158-173.

Forgas, J. P., \& G. H. Bower (1987). "Mood effects on person-perception judgments," 
Journal of Personality and Social Psychology, 53(1), 53-60.

Gorn, G. J., M. T. Pham, \& L. Sin (2001). "When arousal influences ad evaluation and valence does not (and vice versa)," Journal of Consumer Psychology, 11(1), 43-55.

Hirschman, E. C., \& M. B. Holbrook (1982). "Hedonic consumption: Emerging concept, methods and propositions," Journal of Marketing, 46(3), 92-101.

Kim, H., K. Park, \& N. Schwarz (2010). "Will this trip really be exciting? The Role of incidental emotions in product evaluation," Journal of Consumer Research, 36(6), 983991.

Labroo, A. A., \& D. D. Rucker (2010). "The orientation-matching hypothesis: An emotionspecificity approach to affect regulation," Journal of Marketing Research, 47(5), 955-966.

Lerner, J. S., \& D. Keltner (2000). “Beyond valence: Toward a model of emotion-specific influences on judgment and choice," Cognition and Emotion, 14 (4), 473-493.

Libkuman, T. M., P. N. Whitehead, J. Griffith, \& R. Thomas (1999). "Source of arousal and memory for detail," Memory and Cognition, 27(1), 166-190.

Mayer, N. D., \& Z. L. Tormala (2010). “ “Think” versus "Feel" framing effects in persuasion," Personality and Social Psychology Bulletin, 36(4), 443-454.

Mehrabian, A., \& J. A. Russell (1974). An
Approach to Environmental Psychology. Cambridge, MA: MIT Press.

Pham, M. T., M. Geuens, \& P. D. Pelsmacher (2013). "The influence of ad-evoked feelings on brand evaluations: Empirical generalizations from consumer responses to more than 1000 TV commercials," International Journal of Research in Marketing, 30(4), 383-394.

Pham, M. T., J. B. Cohen, J. W. Pracejus, \& G. D. Hughes (2001). "Affect monitoring and the primacy of feelings in judgment," Journal of Consumer Research, 28(2), 167188.

Puto, C. P., \& W. D. Wells (1984). "Informational and transformational advertising: The differential effects of time," in $A d^{-}$ vances in Consumer Research, Vol. 11, Kinnear, T. C., eds., Provo, UT: Association for Consumer Research.

Sanbonmatsu, D. M., \& F. R. Kardes (1988). "The effects of physiological arousal on information processing and persuasion," Journal of Consumer Research, 15(3), 379385.

Schwarz, N., \& G. L. Clore (1983). "Mood, misattribution, and judgment of well-being: Informative and directive functions of affective states," Journal of Personality and Social Psychology, 45(3), 513-523.

Schwarz, N., \& H. Bless (1992). "Constructing reality and its alternatives: An inclusion/ exclusion model of assimilation and contrast 
effects in social judgment," in The Construction of Social Judgments, Martin, L. L., \& Hillsdale, A. T., eds., NJ Lawrence Erlbaum Associates, Inc.

Sobel, M. E. (1982). “Asymptotic confidence intervals for indirect effects in structural equation models," Sociological Methodology, 13, 290-312.

Tversky, A., \& D. Kahneman (1986). "Rational choice and the framing of decisions," Journal of Business, 59(S4), 251-278.

Tversky, A., S. Sattath, \& P. Slovic (1988). "Contingent weighting in judgment and choice," Psychological Review, 95(3), 371384.
Watson, D., L. A. Clark, \& A. Tellegen (1988). "Development and validation of brief measures of positive and negative affect: The PANAS scales," Journal of Personality and Social Psychology, 54(6), 1063-70.

Wegener, D. T., \& R. E. Petty (1994). “Mood management across affective states: The hedonic contingency hypothesis," Journal of Personality and Social Psychology, 66(6), 1034-1048.

Zhang, Y., \& A. Khare (2009). "The impact of accessible identities on the evaluation of global versus local products," Journal of Consumer Research, 36(3), 524-537. 


\section{Appendix I: Utilitarian Attribute-Focused Advertisement}

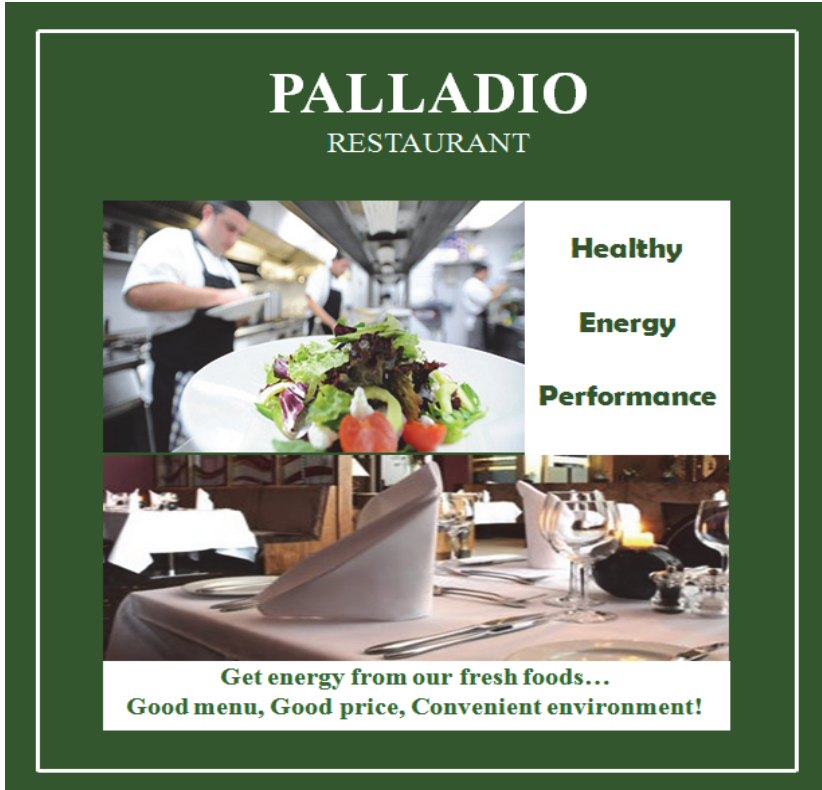

Appendix II: Hedonic Attribute-Focused Advertisement

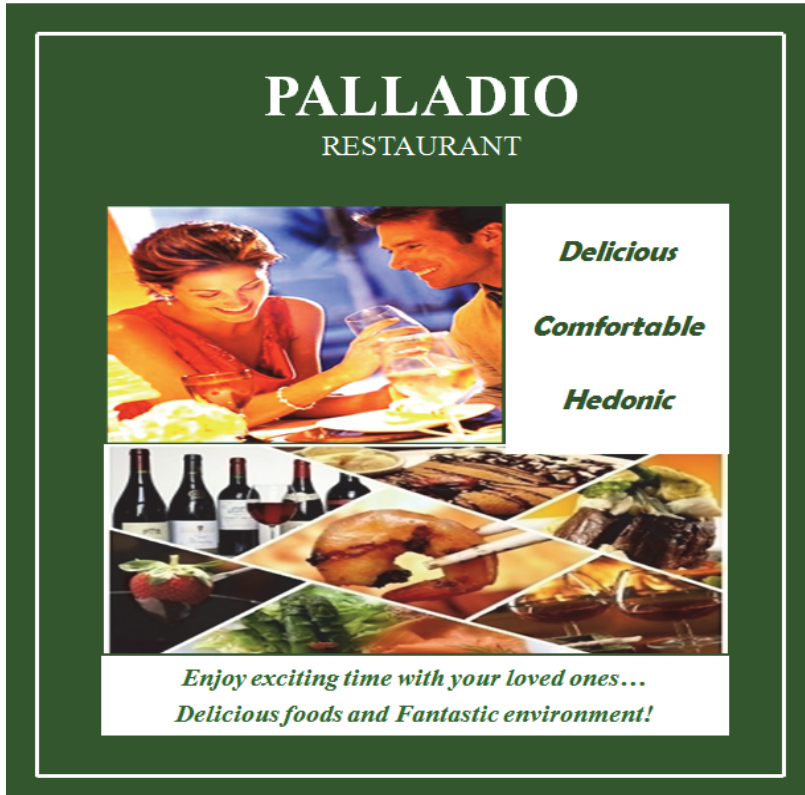




\section{Appendix III: Mild Positive Emotion}

I am a simple college student living apart from my parents. I rely on my parents for my tuition fees and living cost. Even though they work hard to support me, the money they send me is not always sufficient to meet my requirements for the whole expenses of my college life. That's why I have tried to find a part time job compatible with my schoolwork. One day, by just chance, I came across a job offer that would provide me with good terms including the working hours that do not interrupt my class schedule. I had no reason to hesitate but applied to the position. And today, I received a phone call from the boss who notified me to start working from the next week onwards.
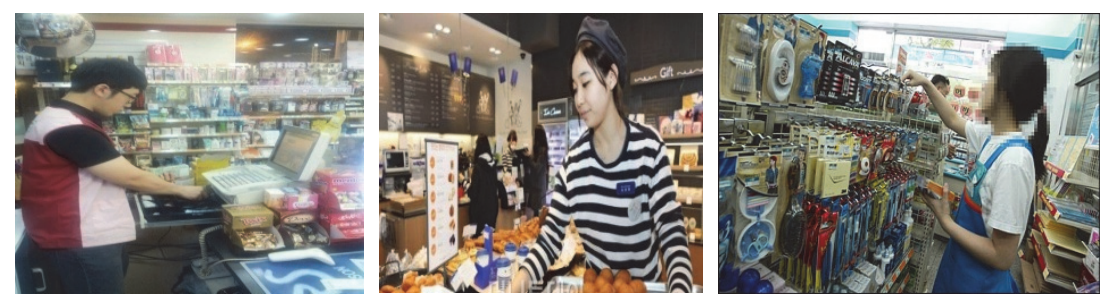

\section{Appendix IV : Elevated Positive Emotion}

I am a senior student at university, and I have studied very hard with the purpose to enter a very famous company. I am eager to achieve this goal successfully because it is not only my biggest dream in my life but also my parents'. My parents have done their best to support me, and I have spent a lot of time, money, and effort to pass the entrance interview. Today, I found out the interview result. YES! I finally did it! I have accomplished my goal! Now I am feeling happy, proud, and excited about this success.

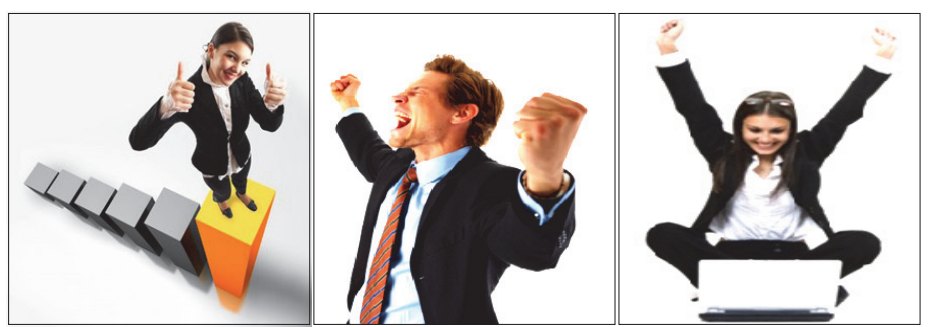

